\title{
O BOURDIEU PRZEJRZYŚCIE I KRYTYCZNIE
}

Tomasz Warczok

Uniwersytet Pedagogiczny w Krakowie

\section{/// Karolina Sztandar-Sztanderska. Teoria praktyki i praktyka teorii. Wstep do socjologii Pierre'a Bourdieu}

Wydana w 2010 r. Teoria praktyki $i$ praktyka teorii autorstwa Karoliny Sztandar-Sztanderskiej to kolejna, po książce Anny Matuchniak-Krasuskiej (2010), pozycja poświęcona teorii socjologicznej Pierre’a Bourdieu. Wcześniej w zakresie tej tematyki mieliśmy jeszcze Iluzje codzienności Małgorzaty Jacyno (1997), opracowanie skądinąd świetne, lecz wydane już ponad 13 lat temu. Od tego czasu pojawiło się kilka nowych pozycji autora Dystynkecji, a i on sam, na kilka lat przed śmiercia, silniej zaznaczył się jako intelektualista publiczny, co nie pozostało bez wpływu na recepcję jego prac.

O ile książka Matuchniak-Krasuskiej dotyczy wybranego obszaru, tzn. socjologii sztuki, to propozycja Sztandar-Sztanderskiej odnosi się do całości teorii francuskiego badacza. Z tego też powodu jest to, bez żadnej wattpliwości, rzecz na polskim rynku niezwykle potrzebna. Od pewnego czasu zauważyć można rosnące zainteresowanie myślą Bourdieu w naszym kraju, co skorelowane jest z sukcesywnym wydawaniem kolejnych tłumaczeń jego książek. Wiemy jednak, że teoria tego autora jest dość skomplikowana, pisana specyficznym, trudnym w odbiorze językiem, dlatego też czytelnicy, szczególnie studenci, którzy chcą się z nią zapoznać, zmuszeni są nierzadko sięgną́ wpierw do opracowań. Z obcojęzycznych pozycji maja do dyspozycji chociażby Pierre Bourdieu et la théorie du monde social Louisa Pinto (2002) bądź znakomite, choć także już nienowe, Culture and Power Davida Swartza (1997). Książka Sztandar-Sztanderskiej wpisuje się w ten nurt wprowadzeń do przebogatej myśli Bourdieu.

Autorka, która dała się już wcześniej poznać jako współtłumaczka $O$ telewizji (Bourdieu 2009), podzieliła swoją książkę na trzy rozdziały. Na początku, w rozdziale pierwszym, przedstawia istotę teorii praktyki Bourdieu 
i ukazuje ją na tle innych ujęć, do których on sam krytycznie nawiązywał. Sa to z jednej strony perspektywy obiektywistyczne, wśród których wyrazistym przykładem jest strukturalizm, z drugiej - szeroko rozumiane podejście fenomenologiczne. Sztandar-Sztanderska pokusiła się w tym miejscu, inaczej niż Bourdieu, o wyodrębnienie perspektywy trzeciej, do której miał on jednoznacznie negatywny stosunek. Chodzi o subiektywizm J.P. Sartre’a. Zabieg podobny zdaje się być interesujący, gdyż pozwala na pełniejsze i klarowniejsze przedstawienie wizji praktyki społecznej Bourdieu, zwanej przezeń wiedzą prakseologiczna.

W opisywanym rozdziale autorka przedstawia także szalenie istotny element omawianej teorii, mianowicie konieczność zorientowania refleksyjnego w procesie badawczym. Brak refleksji nad pozycja badacza nie tylko w szerszej strukturze społecznej, ale i w polu akademickim, oraz niedostrzeganie różnic między stosunkiem do świata zdystansowanego doń teoretyka a nastawieniem tzw. zwykłego człowieka prowadzi do wielu rzadko zauważanych błędów.

W rozdziale kolejnym pojawia się i zostaje szczegółowo wyjaśniona słynna triada pojęciowa, na której wsparty jest cały gmach teorii francuskiego socjologa: habitus - pole - kapitał. Nie bez znaczenia jest wskazanie, jak terminy te funkcjonuja razem, gdyż często zdarza się, również w socjologii polskiej - ale nie tylko (Swartz 2005) - arbitralne wyizolowanie w badaniach empirycznych jednego $z$ tych pojęć, co nierzadko prowadzi do spłaszczania zarysowanej perspektywy i, w konsekwencji, realizowania jej jako kolejnej wersji naiwnego funkcjonalizmu.

Zaleta rozdziału jest przedstawienie sposobów krytycznego potraktowania dorobku Bourdieu. Zabieg taki, daleki od odrzucania teorii francuskiego badacza en bloc, pozwala na zachowanie żywotności tego interesującego ujęcia. Zawsze bowiem istnieje zagrożenie epigońskiej konsekracji ortodoksji, co nie przysparza chwały samej teorii, a także nie przyczynia się do rozwoju nauki społecznej jako takiej. Z „heretyckiego” stanowiska wychodzi Berndard Lahire (2002), którego prace sa nie tylko szeroko cytowane przez autorkę, ale - jak sama pisze we wstępie (s. 11) - stanowiły one inspirację w krytycznym przedstawieniu teorii Bourdieu. Rzecz jest o tyle ciekawa, że badania Lahire'a, dotyczące szeroko rozumianej socjologii kultury i edukacji, są słabo znane poza Francja.

Autorka w przejrzysty sposób rysuje znaczenie podstawowych pojecć, przedstawiając istotę działania, zbliżoną, co jest w książce podkreślone, do wizji „dwoistości struktury” Anthony’ego Giddensa. Działanie społeczne nie jest kwestia kalkulacji czy refleksyjnego poszukiwania 
korzyści, jak przedstawia się to w różnych odsłonach i kolejnych mutacjach teorii racjonalnego wyboru. Działanie pozostaje efektem spotkania habitusu, jako struktury generującej praktyki, z określonym polem. Zgodność tych dwóch sfer, ulokowanie się na pozycji w polu (naukowym, artystycznym, ekonomicznym itd.) odpowiadającej dyspozycji zawartej w habitusie (a będącej efektem długiego procesu socjalizacji) daje wrażenie quasi-naturalnego dopasowania do świata i poczucie bycia na właściwym miejscu. Wszelako nie jest to nigdy proces automatyczny, dopasowanie nie ma w sobie nic mechanicznego: „[...] należy stwierdzić, że o skuteczności podmiotów, prócz zajmowanej przez nie pozycji w strukturach obiektywnych (w strukturze ekonomicznej, wykształcenia itp.), decyduje również umiejętność wykorzystania sytuacji, zaskakiwania konkurentów, siła perswazji, zdolność narzucenia swojej własnej interpretacji. Życie społeczne przypomina grę, która wymaga inwencji w ściśle zakreślonych ramach" (s. 38).

W książce znalazła się także typologia kapitałów: ekonomicznego, kulturowego, społecznego, symbolicznego i dodatkowego - stanowiącego swoisty metakapital - państwowego. Państwo jest dla Bourdieu fundamentalną przestrzenią akumulacji różnego rodzaju kapitałów, dysponuje ono również monopolem na przemoc symboliczna, a więc zdolnością narzucania kategorii postrzegania i oceny, a tym samym naturalizowania społecznych nierówności. Centralną rolę w tym procesie odgrywa szkoła. W drobiazgowych opisach kapitału i pola zabrakło jednakże głębszego wyjaśnienia kategorii, jak się zdaje, kluczowej, czyli pola władzy. Jest to o tyle istotne, że termin ten pozwolił Bourdieu wyjść poza substancjalne odczytywanie jego prac, na rzecz perspektywy z gruntu relacyjnej, która nie zawsze jest właściwie pojmowana. Ta potrzeba tłumaczył potem (Wacquant 1993), dlaczego pojęcie pola władzy, rozumiane jako przestrzeń relacji, w której toczy się nieustanna społeczna gra, zastąiło kategorię klasy dominującej (widzianej przez niektórych, na sposób marksistowski, jako zintegrowana, obdarzona samoświadomościa grupa).

Autorka podjęła również wysiłek wskazania źródeł bądź inspiracji teoretycznych opisywanych pojęć. Kwestia ta wymaga, jak sądzę, doprecyzowania. Otóż przeczytać możemy myśl, wspartą odniesieniem do pracy Lahire'a (s. 48), iż w budowaniu przez Bourdieu teorii pola „,[...] socjologia religii mogła stanowić inspirację w zakresie, w jakim autor ten wyodrębnił różne, autonomiczne i niesprowadzalne do siebie formy działania”. Wiemy z niektórych prac Bourdieu (1987), że nie tylko mogła, ale i była bezpośrednią inspiracją. Z tym że nie chodzi tu raczej o różne 
formy działania, ale o konkretny przykład socjologii religii Maxa Webera - obrazu swoistej gry między prorokiem, czarownikiem a kapłanem. Koncepcja pola pojawiała się za sprawą strukturalnego odczytania tego, jak powiada Bourdieu, nazbyt interakcyjnego (w rozumieniu interakcjonizmu symbolicznego) schematu. Był on później chętnie stosowany w wyjaśnieniach zmagań symbolicznych w różnych polach, a przedstawiony został, w przekształconej wersji, jako niekończąca się walka między siłami ortodoksji (symbolizowanej przez kapłana) i heterodoksji (której ucieleśnieniem byl prorok).

W rozdziale trzecim, ostatnim, zatytułowanym Socjologia jako praktyka społeczna, zarysowana została problematyka pola naukowego, zasad jego funkcjonowania, walki o autonomię i konieczności refleksyjności. $\mathrm{Na}$ tym tle autorka ukazała działalność samego Bourdieu, który coraz wyraźniej, szczególnie od lat 90., angażował się w krytykę neoliberalizmu i w budowę niezależności nauki i innych pól kulturowych. Świat naukowy, jak każde inne uniwersum, jest obszarem zmagań, w których stawką jest, w tym przypadku, kapitał naukowy. Poszczególne idee, teorie naukowe, metodologie są narzędziem w grze o dominację, o ustanowienie prawomocnej wizji nauki, a tym samym pozycji zwierzchniej tych, którzy wizję tę reprezentuja. Warunkiem rozwoju nauki ma być autonomia tego obszaru, a więc takie zakreślenie jego granic, aby nauka odporna była na naciski z zewnątrz, czy to ze świata politycznego, czy to, co dziś wyraźne, ekonomicznego.

Najciekawsza część tego rozdziału odnosi się, jak poprzednio, do prób krytyki stanowiska Bourdieu. Autorka zarzuca mu koncentrowanie się, podobnie jak to uczynił wcześniej w odniesieniu do szerszych dóbr kultury, raczej na producentach (naukowcach), z pominięciem ich produktów (konkretnych treści nauki). Ignorować ma on nawet sama praktykę naukowa i schematy naukowego habitusu: „,[...]«schematy praktyczne», które Bourdieu chce rzeczywiście analizować, nie są opisywanym przezeń habitusem naukowym, dyscyplinarnym, czyli zmysłem praktycznym, schematami percepcji, ocenami działania właściwymi pewnej dziedzinie i używanymi w codziennej aktywności” (s. 79). Krytyka taka, opierająca się właściwie na wnioskach płynących z jednej książki, Science de la science et réflexivité (Bourdieu 2001), która, warto pamiętać, jest raczej zarysem programu badawczego, a nie rezultatem szczegółowych badań pola nauk przyrodniczych, nie jest do końca trafna. Główna słabość, w moim przekonaniu, polega na pominięciu innych pozycji Bourdieu, dotyczących eksploracji pola naukowego czy akademickiego, co odnosi się przede wszystkim do Homo academicus (Bourdieu 1984). W tej analizie francuskiego pola, chociaż 
niekoncentrującej się na naukach przyrodniczych, ale oddającej generalny sposób badania przez Bourdieu reguł działania nauki jako takiej, znajdziemy pełny obraz zarówno pozycji, dyspozycji, jak i schematów mentalnych uczonych. Wyrazistym dowodem na to, że Bourdieu świadom był tego elementu, są inne jego badania, dotyczące tym razem uniwersum filozofii, a konkretnie postaci Martina Heideggera (1988). Mamy tam wyczerpująca analizę schematów, w tym idei politycznych, ukrytych za zawiłościami myśli niemieckiego filozofa.

W rozdziale trzecim autorka rozważa kwestię pewnej niekonsekwencji w praktyce naukowej i publicznej Bourdieu. Z jednej strony bowiem, do początku lat 90 . był on raczej zdystansowany wobec tzw. socjologii krytycznej, widząc w takiej etykietce li tylko rodzaj dystynkcji w polu socjologicznym, potem jednak wyraźne stało się jego krytyczne zaangażowanie, nieograniczone do samego pisarstwa czy badań, ale związane $z$ realnym pojawianiem się na scenie publicznej - także medialnej. O ile zasadnie bronić można jego krytyki neoliberalizmu - wbrew temu, co sądzą niektórzy, były to wysiłki osadzone w badaniach empirycznych, dotyczących chociażby liberalnych przekształceń na rynku mieszkaniowym we Francji (Bourdieu 2000) - to faktycznie pewne wattpliwości budza, jak wskazuje autorka, prace dotyczące pola dziennikarskiego. Książka O telewizjji, chociaż jest interesująca, nie została oparta na rygorystycznej empirii, traktowana może więc być jako wyraz czystej interwencji politycznej w rzeczywistość społeczną. W każdym razie dobrze stało się, że autorka zaprezentowała całość dylematów związanych z działalnością publiczną Bourdieu, przedstawiając także słabo znane w Polsce stanowiska krytyczne w tym względzie.

W moim przekonaniu Karolina Sztandar-Sztanderska spełniła zamiar wyrażony we wstępie pracy - chodziło nie tylko o proste przedstawienie teorii, ale także „[...] szukanie w niej inspiracji, pomysłów na badania empiryczne, pokazanie ograniczeń i niedoskonałości” (s. 13). Mamy obecnie w Polsce taką sytuację, że rosnącemu zainteresowaniu omawianą teorią nie towarzyszą szersze aplikacje empiryczne, które mogłyby ją krytycznie rozwinąć. Ciagle czekamy na polską Dystynkcje, pracę, która nie tylko zaprezentuje lokalną strukturę klasowa, wraz z całym bogactwem specyficznych dla naszego kraju praktyk kulturowych, ale także wniesie, jak to zrobili chociażby badacze brytyjscy (Bennett i in. 2009), wkład w krytyczny rozwój bogatej perspektywy Bourdieu. Wydaje się, że Teoria praktykki i praktyka teorii może stanowić ważną zachętę w podjęciu podobnego wysiłku badawczego, a także realistycznie wyznaczać jego możliwe kierunki. 
Bibliografia:

/// Bennett, T., Savage, M., Silva, E., Warde, A., Gayo-Cal, M., Wright, D. 2009. Culture, Class, Distinction. London-New York: Routledge.

/// Bourdieu, Pierre. 1984. Homo academicus. Paris: Éditions de Minuit.

/// Bourdieu, Pierre. 1987. Legitimation and structured interest in Weber's sociology of religion. W: S. Whimster, S. Lash (ed.). Max Weber, Rationality and Modernity. London-Boston-Sydney: Allen \& Unwin, s. 119-136.

/// Bourdieu, Pierre. 1988. L'ontologie politique de Martin Heidegger. Paris: Éditions de Minuit.

/// Bourdieu, Pierre. 2000. Les structures sociales de l'économie. Paris: Éditions du Seuil.

/// Bourdieu, Pierre. 2001. Science de la science et réflexivité. Paris: Raisons d'Agir.

/// Bourdieu, Pierre. 2009. O telewizji. Panowanie džiennikarstwa. Tłum. K. Sztandar-Sztanderska, A. Ziółkowska. Warszawa: Wydawnictwo Naukowe PWN.

/// Jacyno, Małgorzata. 1997. Iluðje codzৃienności. O teorii socjologicznej Pierre'a Bourdieu. Warszawa: Wydawnictwo Instytutu Filozofii i Socjologii PAN.

/// Lahire, Bernard. 2002. Répéter ou inventer. „Le Monde”, 25.01.2002. http://www.homme-moderne.org/societe/socio/blahire/mortPB.html.

/// Matuchniak-Krasuska, A. 2010. Zarys socjologii sztuki Pierre'a Bourdieu. Warszawa: Oficyna Naukowa.

/// Pinto, Louis. 2002. Bourdieu et la theorie du monde social. Paris: Éditions Albin Michel.

/// Swartz, David. 1997. Culture and Power. The Sociology of Pierre Bourdieu. Chicago-London: The University of Chicago Press.

/// Swartz, David. 2005. Le capital culturel dans la sociologie de l'éducation américaine. W: G. Mauger (ed.). Rencontres avec Pierre Bourdieu. Broissieux: Éditions de Croquant, s. 453-465.

/// Wacquant, L.J.D. 1993. From Ruling Class to Field of Power: An Interview with Pierre Bourdieu on La noblesse d'État. „Theory, Culture and Society” vol. 10, no. 3, s. 19-44. 